\title{
Body Mass Index (BMI) and Dental Caries Experience among Children of Eastern Region of Nepal
}

\author{
Tarakant Bhagat, ${ }^{1}$ Ashish Shrestha, ${ }^{2}$ Santosh Kumari Agrawal ${ }^{3}$ \\ ${ }^{1}$ Associate Professor, ${ }^{2}$ Professor, ${ }^{3}$ Assistant Professor, \\ Department of Public Health Dentistry, B.P. Koirala Institute of Health Sciences, Dharan, Nepal.
}

\begin{abstract}
Introduction: Dental caries and obesity share some common, modifiable influences such as diet and lifestyle including changes in physical activity and food characters. So, obesity can be considered as a predictor of dental caries and various studies have shown the positive association between these two factors.

Objective: The study aims to analyze the relationship between dental caries and BMI in children of eastern region of Nepal.

Methods: A cross-sectional study design was used comprising 600 school children in eastern region of Nepal. Anthropometric measures for the calculation of Body Mass Index (BMI), occurrence of dental caries, missing, and filled teeth due to caries in both the primary and permanent dentition (dft and DMFT respectively) were collected. Data were analyzed using Spearman's correlation and independent $t$ test to assess correlation between dental caries and BMI.
\end{abstract}

Results: Dental caries prevalence was $57.3 \%$. The difference in caries experience among gender was insignificant $(p=0.172)$. Caries experience decreased significantly with increase in years of schooling $(p=0.002)$ and with increase in age $(p<0.001)$. Caries experience increased with an increase in BMI but was not significant $(\mathrm{p}=0.199)$. There was a positive correlation between BMI and DMFT /DMFS but was not statistically significant. The correlation between $\mathrm{dft}$ and dfs was statistically significant.

Conclusions: The study indicated that some form of correlation existed between BMI and dental caries but the association was weak. Healthy with age children experience more caries than overweight and underweight children.

Keywords: BMI, dental caries, eastern Nepal, school children.

\section{INTRODUCTION}

Oral health is strongly influenced by the daily intake of energy-dense foods and drinks, which play a vital role in the development of obesity. The prevalence of childhood obesity has also increased dramatically in many countries around the world and Nepal is not an exception. ${ }^{1}$ Globally, the number of obese children and adolescents rose from 11 million in 1975 to 124 million in 2016 - a tenfold increase. ${ }^{2}$ Childhood obesity rates have recently accelerated, especially in Asia. ${ }^{2}$

\section{Correspondence}

Dr. Tarakant Bhagat

Associate Professor, Department of Public Health Dentistry,

BPKIHS, Dharan, Nepal

E-mail:drtarakant@gmail.com

\section{Citation}

Bhagat T, Shrestha A, Agrawal SK. Body Mass Index (BMI) and Dental Caries Experience among Children of Eastern Region of Nepal. J Nepalese Assoc Pediatr Dent. 2020;1(1):4-7.
High Body Mass Index (BMI) has several consequences on oral health, such as, dental caries, periodontitis, and xerostomia. ${ }^{3}$ Number of studies have shown the positive associations between BMI and dental caries, ${ }^{4,5}$ while others demonstrated no relation ${ }^{6,7}$ or negative association., ${ }^{8,9}$ However, till date no conclusive results have been drawn. Thus, the present study was conducted to analyze the relationship between dental caries and BMI in children of eastern region of Nepal.

\section{METHODS}

A cross-sectional study design was used comprising school children in eastern region of Nepal. Ethical approval was obtained from institutional review committee, B. P. Koirala Institute of Health Sciences (BPKIHS) and consent was obtained from the parents. Permission to examine children was also obtained from the heads of the selected schools. It was a community-based study where the investigator 
visited the randomly selected schools for data collection. Six hundred school children from nursery to class five were taken into the study. It was a purposive sampling where all the primary school children available on the day of examination were enrolled in the study. Sample size was calculated using the formulae mentioned below.

$$
\begin{aligned}
& \text { Sample size }(\mathrm{n})=4 \mathrm{pq} / \mathrm{e}^{2} \\
& \text { where, } \\
& \mathrm{p}=\text { prevalence of dental cari } \\
& \text { school children in Nepal }(67 \%)^{10} \\
& \mathrm{q}=1-\mathrm{p}, \\
& \mathrm{e}=\text { permissible error }(4 \%) \\
& \mathrm{n}=4 \times 67(100-67) / 4^{2}=8844 / 16
\end{aligned}
$$$$
\mathrm{p}=\text { prevalence of dental caries among primary }
$$

Therefore $\mathrm{n}=552.75 \sim 600$

All the children who gave assent and their parents/school principal's signed informed consent were included in the study. Differently abled children, children suffering from any systemic disease, history of prolong illnesses and those who had undergone orthodontic treatment were excluded from the study. The demographic information such as age, sex and address were recorded in a face-to-face interview conducted by the investigators. The occurrence of caries and fillings in the primary dentition, defined as $\mathrm{dft}$ (decayed, filled primary teeth) and permanent dentition, defined as DMFT (decayed, missing and filled permanent teeth), were collected by trained dentists. Anthropometric measures for the calculation of BMI were recorded for each child. The subjects' height in meter and weight in kilogram were recorded to calculate BMI. The children were categorized according to their BMI into underweight,

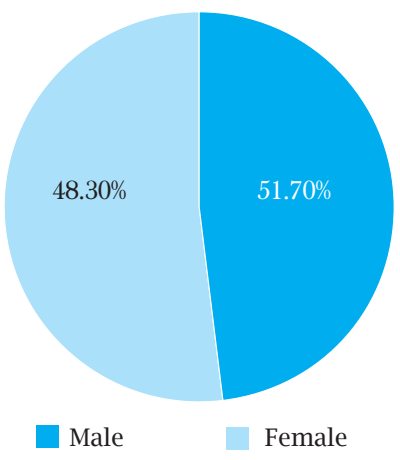

Figure 1. Distribution of subjects according to gender. healthy weight, at risk of overweight, and overweight using the Center for Disease Control and Prevention (CDC) recommendations for $\mathrm{BMI}$ categorizations of children and teen between 2 to 20 years. ${ }^{11}$ Confidentiality and privacy of the students were maintained.

Data was entered in Microsoft Excel sheet and transferred to Statistical Package for Social Sciences (SPSS) version 11.5. Percentage, mean and standard deviation were calculated for all the variables. The results were also analyzed using Chi-square test to compare the difference between all categorical variables. Independent sample $\mathrm{t}$ test and Spearman's ranked correlation test was done for BMI and dental caries. Statistical significance was established at $\mathrm{p}<0.05$.

\section{RESULTS}

Six hundred students participated in the study, among which half (51.7\%) of the participants were female as shown in Figure 1. The mean age of the children was 9.36 \pm 2.45 years. Overall dental caries prevalence was $57.3 \%$ (Figure 2). The prevalence of dental caries was more in females $(60 \%)$ than in males (54.48\%). The difference in caries experience among gender was not significant $\left(\mathrm{X}^{2}\right.$ $=1.864, \mathrm{p}=0.172)$. Mean BMI was $15.18 \pm 2.79$. Mean DT, MT, FT, DMFT and DMFS were $0.34 \pm 0.83,0.00 \pm$ $0.04,0.01 \pm 0.10,0.35 \pm 0.86$ and $0.40 \pm 1.03$, respectively (Figure 3). Similarly, mean dt, ft, dft and dfs were $1.72 \pm$ 2.54, $0.03 \pm 0.21,1.77 \pm 2.59$ and $2.96 \pm 5.20$, respectively (Figure 4). Caries experience decreased significantly with increase in years of schooling $\left(\mathrm{X}^{2}=24.092, \mathrm{p}=0.002\right)$ and with increase in age $(t=-4.027, \mathrm{p}<0.001)$. Caries experience increased with an increase in BMI but was not significant $(\mathrm{t}=-1.285, \mathrm{p}=0.199)$. The positive correlation was found between BMI and DS (=0.063), which was not

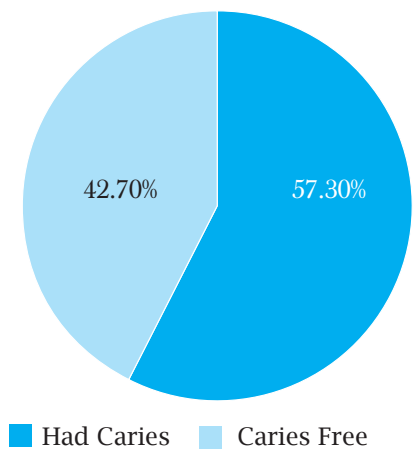

Figure 2. Distribution of subjects according to caries experience. 


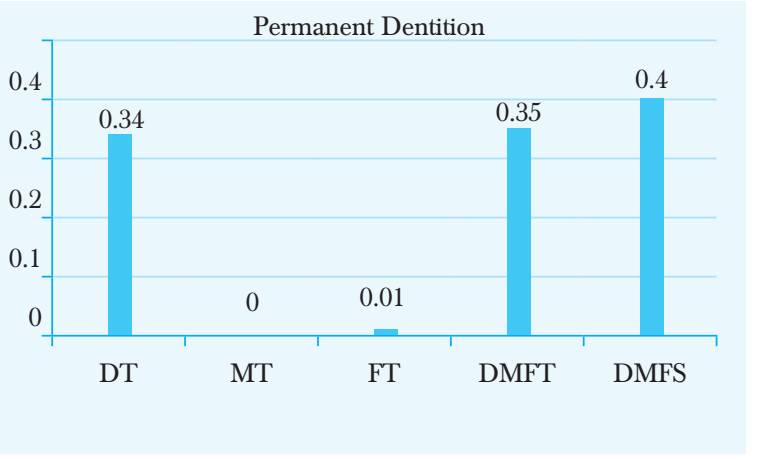

Figure 3. Mean decayed (DT), missing (MT) and filled (FT) permanent teeth.

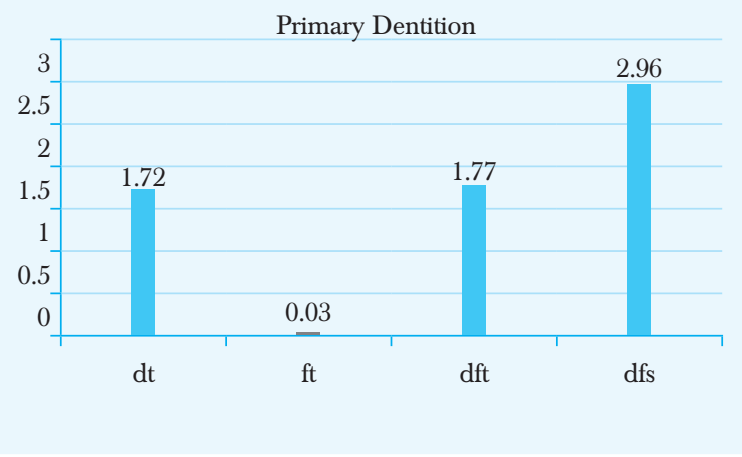

Figure 4. Mean decayed (dt) and filled (ft) primary teeth.

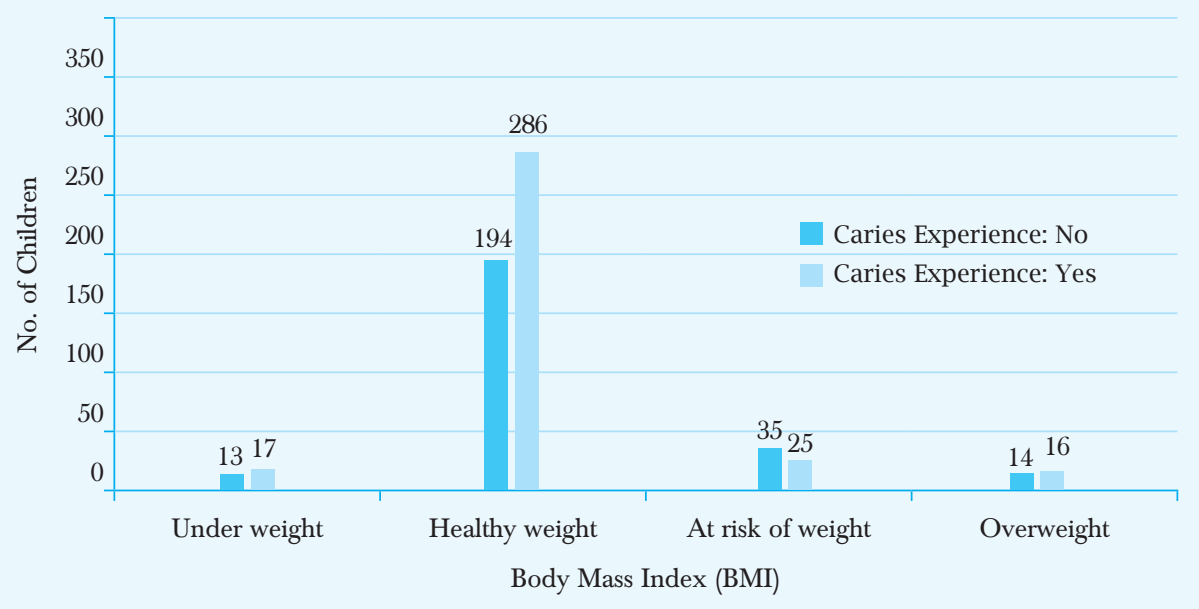

Figure 5. BMI and Caries Experience among participants.

significant $(\mathrm{p}=0.125)$. The correlation between BMI and DMFS was also positive $(\mathrm{p}=0.063)$ but was not significant $(p=0.112)$. There was a positive correlation between BMI and DMFT $(p=0.065)$ but the difference was not statistically significant $(\mathrm{p}=0.114)$. However, negative correlation was observed between BMI and dft ( $p=-1.116)$ and the difference was statistically significant $(\mathrm{p}=0.005)$. Likewise, a negative correlation and statistically significant difference was observed between BMI and dfs ( $p=-1.132$, $\mathrm{p}=0.002)$. There was a positive correlation between $\mathrm{dft}$ and $\mathrm{dfs}(\mathrm{p}=0.981)$ which was statistically significant $(p=<0.001)$. The distribution of caries experience was found more in children who were healthy at weight, while this result showed no significant difference $\left(\mathrm{X}^{2}=7.215\right.$, $\mathrm{p}=0.065)$ (Figure 5).

\section{DISCUSSION}

Obesity is a major public health concern due to its global distribution and severe consequences. ${ }^{3}$ Based on the concept that a common dietary pattern contributes to the development of dental caries and overweight, dental personnel have been suggested to be one of the cornerstones in weight counseling. ${ }^{12}$

However, the present study confirmed that caries experience is positively associated with obesity in the study population but the association was weak and statistically not significant. Present study also showed that healthy children had more caries experience in comparison to overweight or underweight, although the difference was not significant. The observation of the present study was in consistent with several studies related to childhood obesity and dental caries. ${ }^{12-14}$ Few studies also showed negative correlation of dental caries for both DMFT and DMFS with BMI. ${ }^{1,16,17}$ As dental caries and obesity are the multifactorial diseases, certainly, high weight is not per se an etiological factor for the caries process. ${ }^{15}$

The results of the present study showed that the caries experience significantly increases with age and year of schooling. This observation is consistent with the study 
done in Indian public-school children. ${ }^{17}$ One of the possible reason could be that caries is an age-related cumulative condition and thus older group is more likely to exhibit higher values.

However, some limitations must be considered in the present study. Since the data was cross-sectional, causal relationships cannot be established and the observed association could be due to other unexplored factors. Only public school going children were chosen, which represented low socio-economic status and whose population was largely healthy weight thus limiting the possibility of analyzing any possible association between caries and overweight. Thus, future researches should incorporate complete dietary assessments, oral hygiene compliance and other factors that may act as confounders or effect modifiers for assessment of temporal relation between BMI and dental caries.

\section{CONCLUSIONS}

The study indicates that although some correlation does exist between BMI and dental caries the association is weak. Healthy with age children experience more caries than overweight and underweight children. Thus, regular dental checkups and practice of routine oral hygiene procedures reinforcement will enable them to lead a healthier life.

\section{ACKNOWLEDGEMENTS}

I would like to acknowledge BPKIHS for funding this research.

Conflict of Interest: None

\section{REFERENCES}

1. Liang JJ, Zhang ZQ, Chen YJ, Mai JC, Ma J, Yang WH, Jing J. Dental caries is negatively correlated with body mass index among 7-9 years old children in Guangzhou, China. BMC Public Health. 2016 Dec 1;16(1):638. [PubMed I DOI]

2. WHO. New global estimates of child and adolescent obesity released on World Obesity Day.10 October 2017. Retrieved 14 July 2019. Available from: https:// www.who.int/end-childhood-obesity/news/new-estimate-child-adolescent-obesity/en/. [Link]

3. Krishnamurthy K, Bangar BR, Raja A, Gujaral GS, Randive SB, Vaishnav KP, Nayyar AS. Body mass index and its impact on dental caries. Annuals of Tropical Medicine and Public Health. 2017 Jul 1;10(4):810-5. [DOI]

4. Alm A, Fåhraeus C, Wendt LK, Koch G, AnderssonGäre BO, Birkhed D. Body adiposity status in teenagers and snacking habits in early childhood in relation to approximal caries at 15 years of age. International Journal of Paediatric Dentistry. 2008 May;18(3):189-96. [PubMed I DOI]

5. Marshall TA, EichenbergerGilmore JM, Broffitt BA, Warren JJ, Levy SM. Dental caries and childhood obesity: roles of diet and socioeconomic status. Community Dentistry and Oral Epidemiology. 2007 Dec;35(6):449-58. [PubMed I DOI]

6. Dye BA, Shenkin JD, Ogden CL, Marshall TA, Levy SM, Kanellis MJ. The relationship between healthful eating practices and dental caries in children aged 2-5 years in the United States, 1988-1994. The Journal of the American Dental Association. 2004 Jan 1;135(1):55-66. [ubMed I DO]

7. Alves LS, Susin C, DaméTeixeira N, Maltz M. Overweight and obesity are not associated with dental caries among 12yearold South Brazilian schoolchildren. Community Dentistry and Oral Epidemiology. 2013 Jun;41(3):224-31. [PubMed I DOI]

8. Lempert SM, Froberg K, Christensen LB, Kristensen PL, Heitmann BL. Association between body mass index and caries among children and adolescents. Community Dentistry and Oral Epidemiology. 2014 Feb;42(1):53-60. [PubMed I DOI]

9. KopyckaKedzierawski DT, Auinger P, Billings RJ, Weitzman M. Caries status and overweight in 2to 18yearold US children: findings from national surveys. Community Dentistry and Oral Epidemiology. 2008 Apr;36(2):157-67. [DOI]

10. Ministry of Health and Population .National oral health policy 2004 (A.D). [Full Text]

11. Division of Nutrition, Physical Activity, and Obesity, National Center for Chronic Disease Prevention and Health Promotion. Retrieved 3 July 2018. Available from: https://www.cdc.gov/healthyweight/assessing/bmi/childrens_bmi/about_childrens_bmi.html. [Link]

12. Gerdin EW, Angbratt M, Aronsson K, Eriksson E and Johansson I. Dental caries and body mass index by socio-economic status in Swedish children. Community Dentistry and Oral Epidemiology. 2008 Oct;36(5):459-465. [ubMed I DOI]

13. Hong L, Ahmed A, McCunniff M, Overman P, Mathew M. Obesity and dental caries in children aged 2-6 years in the United States: National Health and Nutrition Examination Survey 1999-2002. Journal of Public Health Dentistry. 2008 Sep;68(4):227-33. [PubMed I DOI]

14. Begum MZ, Nagamalleshwari M, Srinivas P, Gadagi JS, Gadde P, Jyothirmai K. Is body mass index truly related to dental caries? Survey on predisposing factors for overweight among Indian school children. Dental Hypotheses. 2014 Oct 1;5(4):150. [DOI]

15. Willerhausen B, Blettner M, Kasaj A, Hohenfellner K. Association between body mass index and dental health in 1,290 children of elementary schools in a German city. Clinical Oral Investigations. 2007 Sep 1;11(3):195-200. [PubMed I DOI]

16. de Jong-Lenters M, van Dommelen P, Schuller AA, Verrips EHW. Body mass index and dental caries in children aged 5 to 8 years attending a dental paediatric referral practice in the Netherlands. BMC Res Notes. 2015;8(1):1-7. [PubMed I DOI]

17. Parkar SM, Chokshi M. Exploring the association between dental caries and body mass index in public school children of Ahmedabad city, Gujarat. SRM Journal of Research in Dental Sciences. 2013 Jul 1;4(3):101. [DOI] 